\title{
Impact of vaccine economic programs on physician referral of children to public vaccine clinics: a pre-post comparison
} Richard K Zimmerman ${ }^{* 11,2}$, Melissa Tabbarah ${ }^{\dagger 1}$, Janine E Janosky ${ }^{1}$, Barbara Bardenheier ${ }^{3}$, Judith A Troy ${ }^{1}$, Ilene K Jewell ${ }^{2}$ and Barbara P Yawn ${ }^{4}$

Address: ${ }^{1}$ Department of Family Medicine and Clinical Epidemiology, School of Medicine, University of Pittsburgh, Pittsburgh, PA, USA, ${ }^{2}$ Department of Behavioral and Community Health Sciences, Graduate School of Public Health, University of Pittsburgh, Pittsburgh, PA, USA, ${ }^{3}$ Health Services Research and Evaluation Branch, Immunization Services Division, National Immunization Program, Centers for Disease Control and Prevention, Atlanta, GA, USA and ${ }^{4}$ Olmsted Medical Group, Department of Research, Rochester, MN, USA

Email: Richard K Zimmerman* - zimmer@pitt.edu; Melissa Tabbarah - tabbarah+@pitt.edu; Janine E Janosky - jej+@ pitt.edu; Barbara Bardenheier - bfb7@cdc.gov; Judith A Troy - judyball@pitt.edu; Ilene K Jewell - ikatz+@pitt.edu;

Barbara P Yawn - yawnx002@GOLD.TC.UMN.EDU

* Corresponding author †Equal contributors

Published: 12 January 2006

BMC Public Health 2006, 6:7 doi: 10.I I86/I47I-2458-6-7
Received: 29 August 2005

Accepted: 12 January 2006

This article is available from: http://www.biomedcentral.com/l47/-2458/6/7

(C) 2006 Zimmerman et al; licensee BioMed Central Ltd.

This is an Open Access article distributed under the terms of the Creative Commons Attribution License (http://creativecommons.org/licenses/by/2.0), which permits unrestricted use, distribution, and reproduction in any medium, provided the original work is properly cited.

\begin{abstract}
Background: The Vaccines for Children (VFC) Program is a major vaccine entitlement program with limited long-term evaluation. The objectives of this study are to evaluate the effect of VFC on physician reported referral of children to public health clinics and on doses administered in the public sector.
\end{abstract}

Methods: Minnesota and Pennsylvania primary care physicians $(n=164)$, completed surveys before (e.g., 1993) and after (2003) VFC, rating their likelihood on a scale of 0 (very unlikely) to 10 (very likely) of referring a child to the health department for immunization.

Results: The percentage of respondents likely to refer was $60 \%$ for an uninsured child, $14 \%$ for a child with Medicaid, and $3 \%$ for a child with insurance that pays for immunization. Half (55\%) of the physicians who did not participate in VFC were likely to refer a Medicaid-insured child, as compared with $6 \%$ of those who participated $(P<0.001)$. Physician likelihood to refer an uninsured child for vaccination, measured on a scale of 0 to 10 where 10 is very likely, decreased by a mean difference of I.9 $(P<0.00 I)$ from pre- to post-VFC. The likelihood to refer a Medicaid-insured child decreased by a mean of I.2 $(P=0.00 \mathrm{I})$.

Conclusion: Reported out-referral to public clinics decreased over time. In light of increasing immunizations rates, this suggests that more vaccines were being administered in private provider offices.

\section{Background}

Although immunization rates for preschool children in the United States are high by historical standards, pockets of need exist and racial disparity occurs $[1,2]$. The Healthy People 2010 vaccination coverage goal for universally rec- ommended vaccinations among children aged 19-35 months is $90 \%$ [3]. Economic barriers are among the barriers to achieving this goal. In 1992, a national study reported that more than $85 \%$ of physicians reported refer- 
ring uninsured children to public vaccine clinics some of the time [4].

To address economic barriers, vaccine financing reforms, such as the Vaccines for Children Program (VFC), were developed and followed by a reduction in the proportion of physicians that refer children to public clinics for vaccination [5]. Begun in October 1994, the VFC provides states with free vaccines for children who are Medicaid-eligible, have no health insurance, or are Native Americans or Alaskan natives [6]. In addition, children whose insurance does not cover vaccines are eligible for VFC if they are vaccinated at a federally qualified health center or rural health clinic. Other studies reported that both VFC and state laws requiring indemnity insurers to cover childhood immunizations contributed to the decrease in proportion of physicians who referred children to public vaccine clinics for immunizations, where free vaccines were available [7-9]. To investigate the progress on economic barriers, we sought to compare post-VFC data with pre-VFC data. Specifically, given our previous data on reported out-referral in Minnesota and Pennsylvania prior to the VFC program [10-12], we determined the reported out-referral of children by insurance status now, a decade later.

\section{Methods}

We conducted a mailed survey of physicians and obtained doses administered data from the public sector.

\section{Subjects}

For the 2003 survey, we recruited primary care physicians in Minnesota and Pennsylvania who participated in a previous survey on vaccine economics in 1991 or 1993 (State dependent) [10-12]. Minnesota physicians were initially sampled systematically based on a random start point from the Minnesota Medical Association (MMA) master list using four strata: general practitioners (GPs), boardcertified family physicians (FPs) in urban and suburban areas, board-certified FPs in rural areas, and board-certified pediatricians (Peds). The initial Pennsylvania physicians came from a random sample of GPs, FPs, and Peds from the combined listings of the American Medical Association and the American Osteopathic Association [11].

We surveyed 340 primary care physicians in 2003 from Minnesota and Pennsylvania, of whom 26 were determined ineligible because they had retired, died, no longer saw children, or moved out of state. Of the remainder, 118 could not be reached, and 22 refused, leaving 174 physicians. We excluded 10 physicians who returned surveys anonymously. Our sample in 2003 was thereby reduced to 164 physicians ( 89 from Minnesota and 75 from Pennsylvania) who completed the survey for a response rate of $54 \%(164 / 304)$; the refusal rate was $7 \%$.
All 164 physicians were surveyed previously in 1991 or 1993. Before the study, power calculations determined that the sample size required for the matched pair analyses to detect a difference of $10 \%(0.5)$ based on a mean response of 5 with a standard deviation of 2.0 on a scale of 0 to 10 was at least 126 respondents to have statistical power of 0.80 with a type I error rate of 0.05 . Unfortunately, we were unable to test for demographic differences among physicians over time (i.e., 1991 or 1993 vs. 2003 data) because we were unable to access data from 1991 or 1993.

\section{Questionnaire}

We chose PRECEDE-PROCEED, a systematic process to evaluate health problems and design intervention programs $[13,14]$, as the framework for concepts on the questionnaire. This framework allowed us to include various barriers and facilitators to vaccination, including economics and insurance. For many questions, respondents were asked to rate on a scale of 0 (very unlikely) to 10 (very likely) how likely they were to recommend immunization for a child in a particular clinical situation (e.g. uninsured, Medicaid, or insured child). The questionnaire was pilottested and subsequently revised [15].

\section{Data collection}

Data were collected by questionnaires mailed in three waves; data from completed questionnaires were entered twice and compared to reduce data entry errors. Nonrespondents to the third wave were contacted by trained interviewers using computer-assisted telephone interviewing (CATI) which allowed direct data entry during the interview [16], eliminated unintentionally skipped questions, and provided automatic range and logic checks. Data collection began in January 2003 and continued into August 2003. Participants were offered a $\$ 30$ honorarium. The Institutional Review Board of the University of Pittsburgh, Olmsted Medical Center, and the Centers for Disease Control and Prevention approved this project.

\section{Statistics}

For a clearer presentation of the data and due to our modest sample, the likelihood of referring children to the public health department for immunizations which was rated on scales of $0-10$, was collapsed into the categories: "unlikely" (rating 0-5) and "likely" (rating 6-10). This categorization was chosen because of the bimodal distribution. Changes in the number of referrals since 1993 and the impact programs had on referral to public vaccine clinics were collapsed into "decrease" (rating 0-3) "no change" (rating 4-6) and "increase" (rating 7-10). Adequacies of Medicaid were rated on a scale of $0-10$ were collapsed into "inadequate" (rating 0-3), "intermediate adequacy" (rating 4-6), and "adequate" (rating 7-10). Chi-square tests for associations were performed on the 
Table I: Demographic characteristics of physician respondents by state

\begin{tabular}{lcc}
\hline Variable & $\begin{array}{c}\text { Minnesota } \\
(\mathrm{n}=89)\end{array}$ & $\begin{array}{c}\text { Pennsylvania } \\
(\mathrm{n}=75)\end{array}$ \\
\hline $\begin{array}{l}\text { Gender }(\% \text { male) } \\
\text { Specialty }\end{array}$ & 75 & 71 \\
$\quad$ Family Practitioner/General Practitioner & 51 & 47 \\
$\quad$ Pediatrician & 49 & 53 \\
Number of primary care physicians in practice & & 26 \\
(\%) & 36 & 29 \\
$0-2$ & 27 & 45 \\
$3-5$ & 37 & $42.8(3.8)$ \\
$\quad 6+$ & $60.6(15.4)$ & $98(0.5)$ \\
Number of patients under age 6 years seen in a & $96(0.8)$ & \\
typical week, (mean \pm SE) & & $5(0.7)$ \\
Percentage of primary care patients, (mean \pm & $6(0.7)$ & $12(2.7)$ \\
SE)* & $11(1.9)$ & $40(2.7)$ \\
Percentage of patients with payment type & $40(3.4)$ & $20(2.5)$ \\
$\quad$ Self pay or uninsured (mean \pm SE) & $18(2.6)$ & $4(1.1)$ \\
$\quad$ Medicaid HMO (mean \pm SE) & $7(1.3)$ & \\
$\quad$ Commercial HMO/PPO (mean \pm SE) & & \\
$\quad$ Fee for service insurance (mean \pm SE) & & \\
$\quad$ Traditional Medicaid (mean \pm SE)** & & \\
\hline
\end{tabular}

Means are reported with standard error (SE).

$* P<0.01$ by $t$ test.

** $P<0.05$ by $\mathrm{t}$ test.

contingency tables. Student's t tests were performed to test for group differences of continuous variables. Paired $t$ tests were used to test for pre- versus post-VFC differences in physician ratings. Multiple linear regression analyses to determine which variables predict physician likelihood of referral to public vaccine clinics did not contribute additional information already obtained from the bivariate analyses. Therefore, we did not report these models. All statistical analyses were achieved by using SAS 8.2 statistical software (SAS Inc, Cary, North Carolina). Statistical significance was set at $P \leq 0.05$.

\section{Results}

\section{Demographics}

The demographic characteristics of Minnesota and Pennsylvania physicians were generally similar (Table 1). However, Minnesota respondents saw a somewhat lower percentage of primary care patients than Pennsylvania physicians $(96 \%$ vs. $98 \%, P=0.007)$.

\section{Impact of insurance status on referral to health department clinics for immunizations}

Physicians were asked in 2003 to rate their likelihood on a scale of 0 (very unlikely) to 10 (very likely) of referring a child to the health department for immunization in a series of survey questions in which only the insurance status of the patient changed. The percentage of respondents likely to refer was $60 \%$ for an uninsured child whose parents are unable to pay, $50 \%$ for a child with insurance that did not cover vaccines, $14 \%$ for a child with Medicaid, and
$3 \%$ for a child with insurance that pays for immunization. There were no state differences in referring Medicaidinsured children, children with insurance that pays for immunization, and children whose insurance did not pay for vaccine; however, Minnesota physicians (68\%) reported being more likely than Pennsylvania physicians (51\%) to refer uninsured children whose parents were unable to pay $(P=0.024)$.

The majority of physicians (57\%) reported a higher likelihood of referring an uninsured child as compared with a child with insurance coverage to a health department vaccine clinic; $65 \%$ of these physicians participated in VFC and $16 \%$ did not know about their VFC participation. Of those physicians who would not refer either child (38\%), the majority (87\%) participated in VFC and 5\% did not know about their VFC participation. Only 2\% of physicians reported that they would refer both insured and uninsured children for vaccination.

\section{Participation in VFC and impact on referral to health department for immunization}

The proportions of Minnesota and Pennsylvania physicians, respectively, participating in VFC was $71 \%$ and $76 \%$, nonparticipating was $11 \%$ and $19 \%$ and did not know was $17 \%$ and $5 \%(P=0.041)$. More physicians who did not participate in VFC were likely to refer children to the health department for immunizations than those who participated (Figure 1). The difference was especially marked with regard to Medicaid children, for whom 55\% 


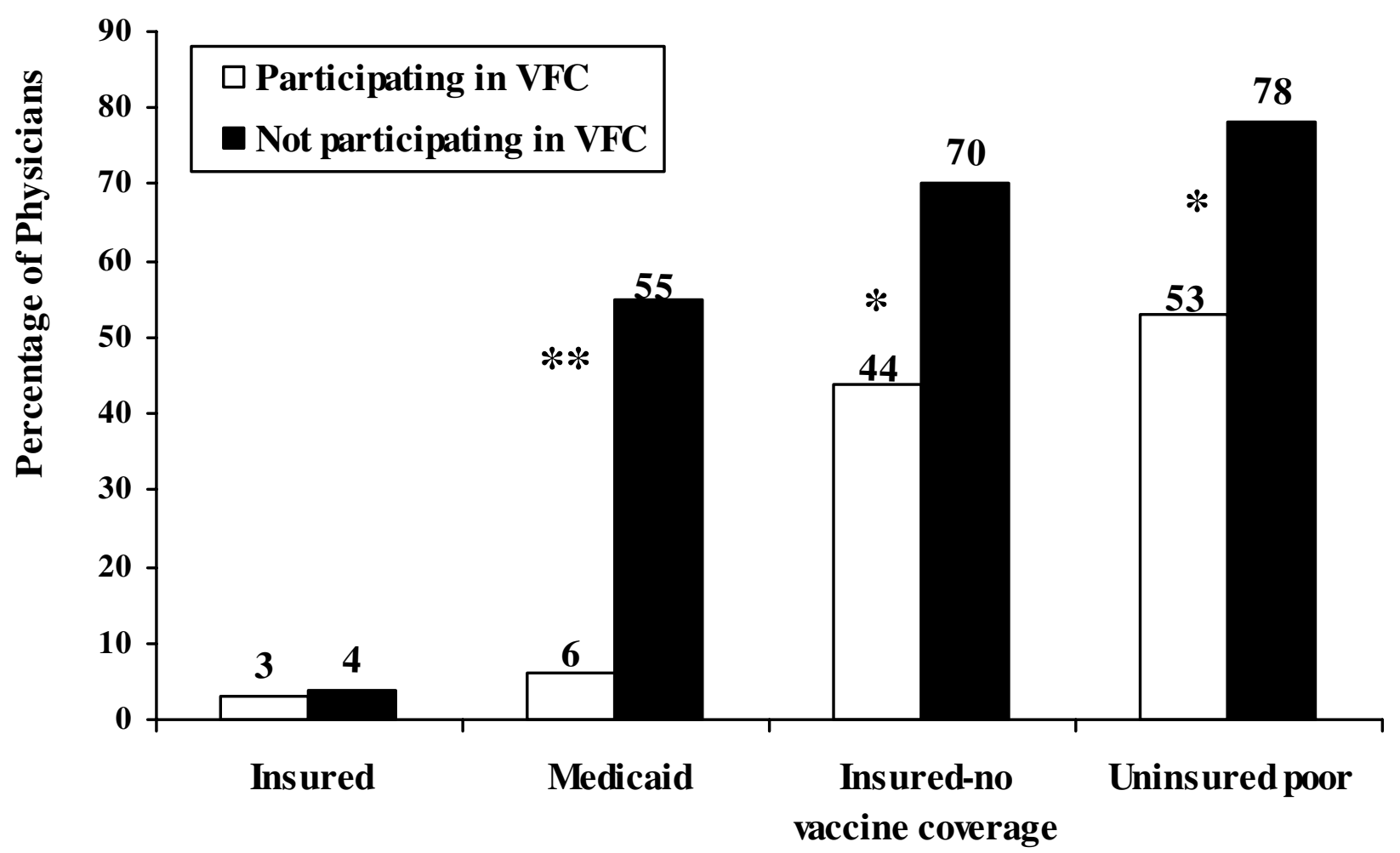

Figure I

Percentage of physicians in 2003 likely to refer children to public health department vaccine clinics by participation in VFC and by patient insurance status. Vaccine, Zimmerman, RK, et al. Legend: Likely is defined as 6 to 10 on a scale of 0 to I0. ** P $\leq$ $0.001 * P \leq 0.05$

of the physicians who did not participate were likely to refer as compared with $6 \%$ of those who participated in VFC $(P<0.001)$.

When state comparisons were made, similar results were found for referral of insured and insured without vaccine coverage; however state differences were apparent for Medicaid-insured and uninsured children. Comparing physicians who participated and did not participate in VFC, the likelihood of out-referring a Medicaid-insured child was $5 \%$ versus $77 \%(P<0.001)$ in Pennsylvania and $6 \%$ versus $22 \%(P=0.123)$ in Minnesota. Comparing physicians who participated and did not participate in VFC, the likelihood of out-referring an uninsured child was $40 \%$ versus $86 \%(P=0.002)$ in Pennsylvania and $65 \%$ versus $67 \%$ in Minnesota $(P=0.922)$.

\section{Determinants of self-reported change in out-referral}

Almost a quarter (24\%) of physicians reported decreased referrals of children to public vaccine clinics in a question about changes in the number of referrals since 1993. The impact being greater in Pennsylvania than Minnesota $(\mathrm{P}<$ 0.01; Table 2). The VFC program and Children's Health Insurance Program (CHIP) are associated with changes in reported referral since 1993 (Table 2).

Over a third of physicians (34\%) reported that the VFC program decreased the number of referrals from their practice to public vaccine clinics, $7 \%$ reported increased referrals, and $60 \%$ gave intermediate responses. The impact differed by state: $23 \%$ of Minnesota physicians reported decreased referrals because of VFC compared with $45 \%$ for Pennsylvania physicians $(P=0.003)$. 
Table 2: Change in reported referrals to public vaccine clinics from 1991/1993 to 2003, by perceived impact of VFC and CHIP, on referrals

\begin{tabular}{|c|c|c|c|c|}
\hline \multirow[t]{2}{*}{ Variable } & \multicolumn{4}{|c|}{ How has the number of child referrals to public vaccine clinics changed since 1993} \\
\hline & Decrease (\%) & Same (\%) & Increase (\%) & Total (\%) \\
\hline Overall & 24 & 66 & 10 & 100 \\
\hline \multicolumn{5}{|l|}{ State* } \\
\hline Minnesota & 18 & 76 & 6 & 100 \\
\hline Pennsylvania & 31 & 55 & 15 & 100 \\
\hline \multicolumn{5}{|l|}{$\begin{array}{l}\text { Impact of VFC on } \\
\text { referrals* }\end{array}$} \\
\hline Decrease & 62 & 25 & 13 & 100 \\
\hline No change & 1 & 93 & 6 & 100 \\
\hline Increase & 36 & 36 & 27 & 100 \\
\hline \multicolumn{5}{|c|}{$\begin{array}{l}\text { Impact of CHIP on } \\
\text { referrals* }\end{array}$} \\
\hline Decrease & 55 & 32 & 13 & 100 \\
\hline No change & 11 & 84 & 5 & 100 \\
\hline Increase & 36 & 27 & 36 & 100 \\
\hline
\end{tabular}

$* P<0.01$ by $X^{2}$ test.

Almost a quarter (24\%) of physicians reported that CHIP decreased the number of such referrals, $7 \%$ reported increased referrals, and $69 \%$ gave intermediate responses. This also varied by state: $15 \%$ of physicians in Minnesota reported decreased referrals attributed to CHIP compared with $35 \%$ of physicians in Pennsylvania $(P=0.003)$. In Pennsylvania, $27 \%$ of physicians reported that the "first dollar" law decreased the number of referrals, $10 \%$ reported increased referrals, and $63 \%$ gave intermediate responses.

\section{Medicaid issues}

Few physicians (12\%) thought that the reimbursement by traditional Medicaid for the vaccine administration fee was adequate; $51 \%$ thought it was inadequate, and $37 \%$ gave intermediate answers. Perceptions of the adequacy of this administration fee did not vary by state. Even fewer physicians $(10 \%)$ felt that the monthly capitation rate from Medicaid HMOs was adequate; over half (56\%) rated it as very inadequate, and over a third (34\%) gave intermediate responses. Adequacy of the monthly capitation rate from Medicaid HMOs did vary by state with more Pennsylvania physicians reporting that it was inadequate than Minnesota physicians $(69 \%$ vs. $45 \%, P=$ $0.005)$. Neither the perceived adequacy of the Medicaid vaccine administration fee nor the adequacy of the monthly capitation rate was related to the likelihood of referral of a Medicaid-insured child.

\section{Historical comparisons of out-referral before and after VFC}

Comparisons of physician likelihood to out-refer using data from the surveys conducted before VFC and after VFC implementation revealed a significant drop in the likeli- hood to out-refer. Physician likelihood to refer an uninsured child for vaccination, measured on a scale of 0 to 10 points where 10 is very likely, decreased by a mean difference of 1.9 points $(P<0.001)$ from pre- to post-VFC. The likelihood to refer a Medicaid-insured child decreased by a mean of 1.2 points $(P=0.001)$. For an insured child, there was mean decrease of $0.7(P=0.01)$. When these data are stratified by state, there was a decrease in the likelihood of MN physicians to refer a Medicaid insured child by a mean difference of 0.7 points $(P=0.05)$. Among PA physicians, we found a decrease in their likelihood of referring an uninsured child for vaccination by 3.8 points $(P<0.001)$ and a decrease in their likelihood of out-referrals for Medicaid insured children by 2.5 points $(P<$ $0.001)$.

\section{Discussion}

To our knowledge, this is the only study of vaccine economics over a decade that had baseline data from interviews conducted before the VFC and could directly match individual responses for a true pre-post comparison.

We found that physicians' reported likelihood of referring children to public vaccine clinics decreased from before VFC to after its implementation and that VFC and CHIP were credited for this decrease. Differential referral based on insurance status continues to occur, especially for clinicians who are not participating in VFC. Clinicians who are participating are much more likely to vaccinate Medicaid and uninsured children in their office. Previous reports attributed decreased out-referrals of children for immunizations to the VFC $[7,17]$, to changes in state insurance coverage laws $[7,17]$, and to a universal vaccine purchase program [18]. Moreover, inner city physicians 


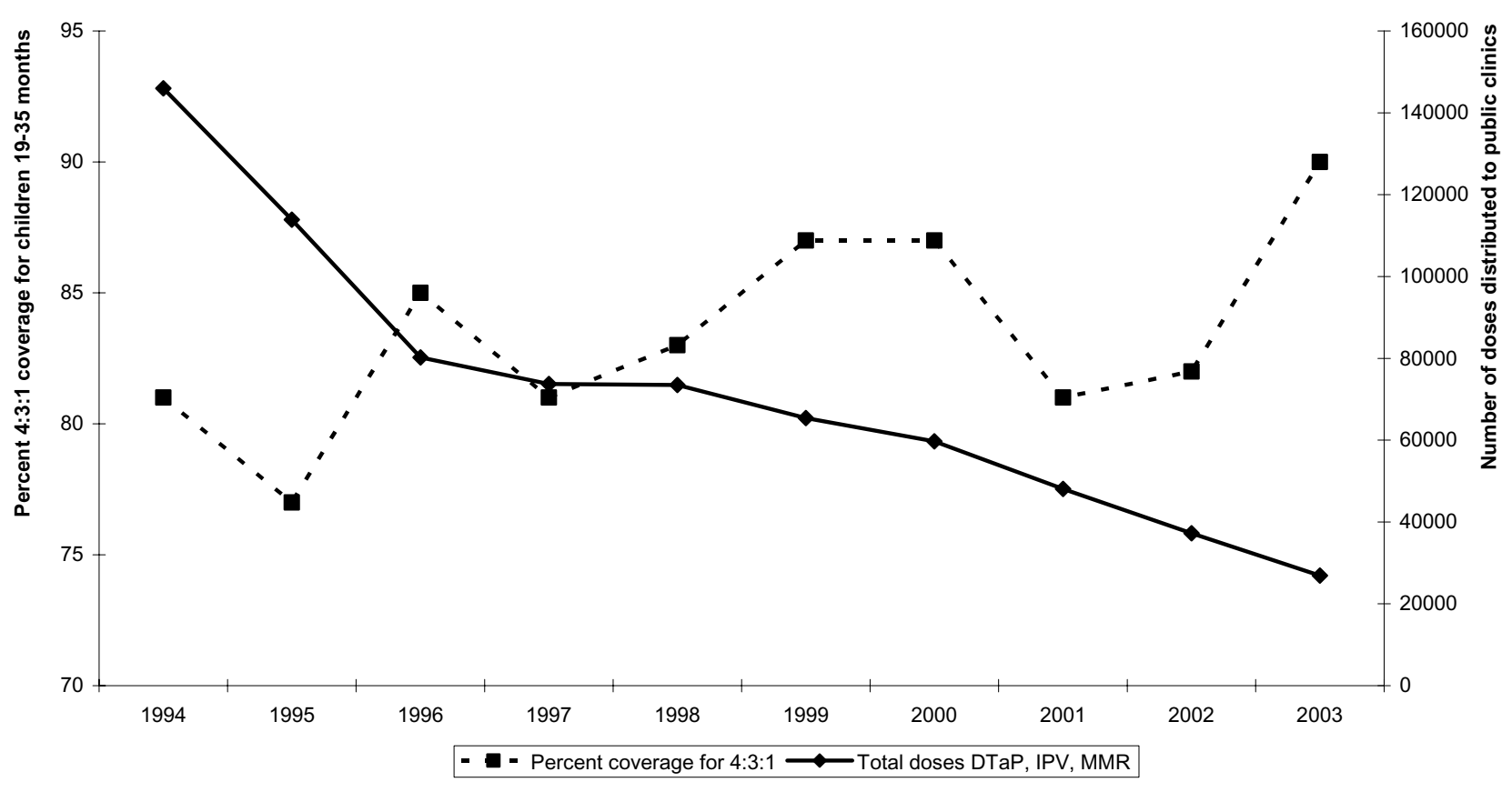

Figure 2

Total doses DTP, polio and MMR vaccines administered at Minnesota health departments and overall 4:3:I vaccine coverage rates for Minnesota, 1994-2002. Vaccine, Zimmerman, RK, et al.

generally attributed increased immunization rates to the VFC [19].

Generally, Minnesota and Pennsylvania have progressive immunization financing systems. A first dollar immunization coverage law was implemented in 1988 in Minnesota and in 1992 in Pennsylvania that enables insured children to receive vaccines at their private physicians' offices. The VFC program was implemented on October 1, 1994 in Minnesota, on January 1, 1995 in Philadelphia, and April 1, 1996 in Pennsylvania generally. The first dollar laws greatly reduce under-insurance for immunization; however, certain plans are exempt [i.e., ERISA (Employee Retirement Income Security Act) plans]. The children who remain under-insured can be vaccinated in their medical home in Minnesota, using vaccine typically purchased by the state; in Pennsylvania, the under-insured can be referred for vaccination to public health vaccine clinics or federally qualified health centers where VFC vaccine can be used for the under-insured. Despite these differences, we found no difference between the states in out-referral of under-insured children which we speculate is due to the success of first dollar laws, the limited number of ERISA plans, or good vaccine coverage with ERISA plans.
Given the billion dollar cost of VFC, it is critical to have data to collaborate our survey data. In the current study, we report substantial decreases in doses administered by public health agencies in MN and PA since 1993 [See Figures 2 and 3], [see Additional file 1]. Because overall immunization rates have been increasing, the decline in vaccinations given by public health agencies is consistent with increased vaccinations given by private clinicians. Szilagyi et al [20], found that the number of childhood vaccinations delivered at health department clinics in PA declined 56\% between 1993 and 1997 in PA.

A possible explanation for decline in number of vaccine doses administered by health departments [See Additional file 1] may be decreases in public health staffing due to either federal Section 317 or state funding reductions. PA began examining the transfer of some state health clinic functions including immunizations, in 1996. The study's authors reported that immunization services could be as effectively delivered by the private sector as by public health departments in both urban and suburban areas, but not in rural areas [21]. However, this demonstration project was neither large enough, nor early enough to explain observed declines in public sector vaccinations in PA. 


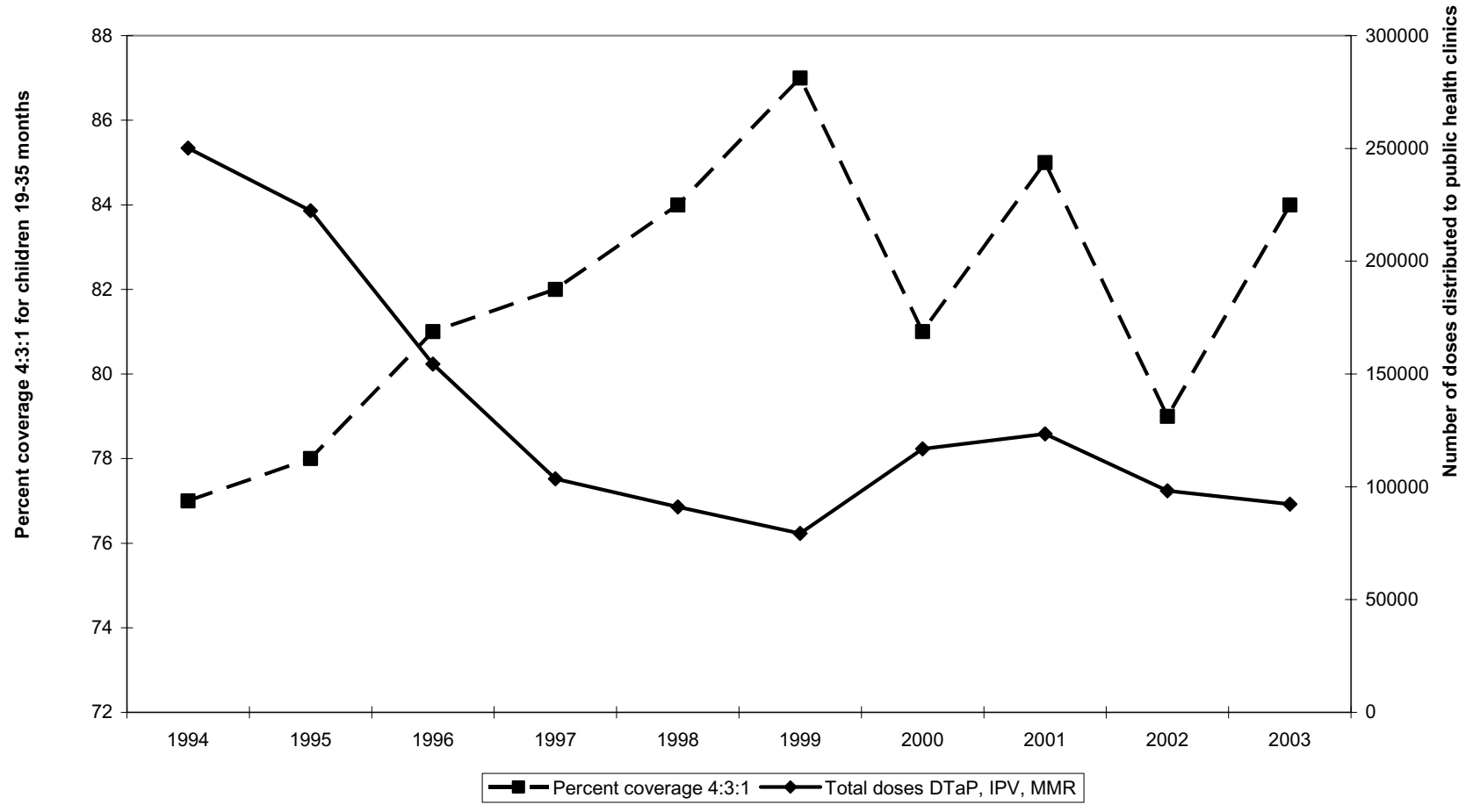

\section{Figure 3}

Total doses DTP, polio and MMR vaccines administered at Pennsylvania health departments and overall 4:3:I vaccine coverage rates for Pennsylvania, 1994-2002. Vaccine, Zimmerman, RK, et al.

\section{Outcome of referral of disadvantaged children to public vaccine clinics}

Although referral of children from primary care physician's offices to public vaccine clinics is preferable to not vaccinating, there are disadvantages. First, the child may visit the public vaccine clinic late and therefore have a window of time when they are not age-appropriately vaccinated and therefore are susceptible to vaccine-preventable diseases. Second, fragmentation of care occurs with an increased burden and expense for the parents of taking the child to one site for vaccines and another site for wellchild care and other services. A study after VFC implementation found that $73 \%$ of children received all or some immunizations within a medical home [22]. Another study found that the percentage of children up-to-date with DTaP was $2 \%-9 \%$ lower when comparing records from the most recent provider with a fuller set of records [23]. Third, until wider use of immunization registries, medical records are not easily transferred from one site to another and therefore each site may lack important information available at the other.

\section{Limitations}

This study has certain limitations. The response rate was modest. It is impossible to know to what extent, if any, the non-respondents differ with regard to their current demographics, attitudes and practices concerning vaccine economics. By design, this sample represents physicians, who have been in practice over a decade, not all physicians in current practice. Arguably, the results cannot be generalized beyond the states of Minnesota and Pennsylvania; however, the 2002 4:3:1:3:3 immunization series (e.g., of 4 doses of DTP, 3 doses of poliovirus vaccine, 1 dose of measles containing vaccine, 3 doses of Hib, 3 doses of Hepatitis B vaccine) completion rates in these two states were $77 \%$ and $75 \%$, respectively, which are fairly close to the national rate of $75 \%$ [24]. In addition, these two states represent two very different socio-political environments, one a predominantly rural, large, midwestern region and the other, a more urban, Eastern region. Finally, beforeand-after studies on the same individuals identify changes but do not necessarily prove the reason for the changes. Because several policy and programmatic changes occurred during this time period, ability to attribute changes to any one program may be limited. However, the addition of doses administered in the public sector greatly strengthens the conclusions. 


\section{Conclusion}

Reported out-referral by primary care physicians to public vaccine clinics decreased from 1991-1993, that is before VFC, to this 2003 study. Fewer doses being administered at health departments coupled with higher rates of immunizations, suggest that more vaccines were being administered in private provider offices.

\section{Competing interests}

The author(s) declare that they have no competing interests.

\section{Authors' contributions}

Richard Kent Zimmerman, MD, MPH: Funding, design, data interpretation, manuscript writing

Melissa Tabbarah, PhD, MPH: Data analyses, manuscript writing

Janine E. Janosky, PhD, Advice on data analyses and interpretation/ senior statistician

Barbara Bardenheier, MPH, MA, Epidemiologic advice, data interpretation, manuscript editing

Judith A. Troy, MS, Data collection, manuscript assistance

Ilene K. Jewell, MS Hyg, Instrument design, data collection

Barbara P. Yawn MD, Msc. Assistance with recruitment, interpretation of data

\section{Additional material}

\section{Additional File 1}

"Methods: Vaccine doses administered in the public sector" and "Results: Doses Administered". Minnesota and Pennsylvania state health departments provided data on doses of diphtheria-tetanus-pertussis (DTP or $D T a P)$, poliovirus, and measles-mumps-rubella vaccines (MMR) administered in their respective states for the years 1994-2003. Immunization rates for these states for the years 1994-2003 were obtained from the National Immunization Survey. These data are graphed by year in Figures 2 and 3.

Click here for file

[http://www.biomedcentral.com/content/supplementary/14712458-6-7-S1.doc]

\section{Acknowledgements}

Mary Patricia Nowalk, PhD for graphing the doses administered data; Lisa Harris and Nancy Mumper for providing the doses administered data.

This project was made possible through a cooperative agreement between the Centers for Disease Control and Prevention and the Association of Teachers of Preventive Medicine, award number TS 0897; its contents are the responsibility of the authors and do not necessarily reflect the official views of the CDC or ATPM.

\section{References}

I. National, state, and urban area vaccination levels among children aged 19-35 months--United States, 2002. MMWR Morb Mortal Wkly Rep 2003, 52:728-732.

2. Chu SY, Barker LE, Smith PJ: Racial/ethnic disparities in preschool immunizations: United States, 1996-200 I. Am J Public Health 2004, 94:973-977.

3. U.S.Department of Health and Human Services: Healthy People 2010. 2000 [http://www.healthypeople.gov/document/tableofcon tents.htm].

4. Ruch-Ross HS, O'Connor KG: Immunization referral practices of pediatricians in the United States. Pediatrics 1994, 94:508-513.

5. Zimmerman RK, Medsger AR, Ricci EM, Raymund M, Mieczkowski TA, Grufferman S: Impact of free vaccine and insurance status on physician referral of children to public vaccine clinics. Journal of the American Medical Association 1997, 278:996-1000.

6. Centers for Disease Control and Prevention: Vaccines for Children Program. 2005 [http://www.cdc.gov/nip/vfc/Default.htm].

7. Szilagyi PG, Humiston SG, Shone LP, Kolasa MS, Rodewald LE: Decline in physician referrals to health department clinics for immunizations: the role of vaccine financing. Am J Prev Med 2000, 18:318-324.

8. Zimmerman RK, Nowalk MP, Mieczkowski TA, Mainzer HM, Jewell IK, Raymund M: The Vaccines for Children Program: Policies, Satisfaction and Vaccine Delivery. Am J Prev Med 200I, 2 I:243-249.

9. Medicine I, Committee on the Evaluation of Vaccine Purchase Financing in the United States, Services BHC: Financing Vaccines in the 2 Ist Century National Academies Press; 2004.

10. Zimmerman RK, Mieczkowski TA, Mainzer HM, Medsger AR, Nowalk MP: Understanding physician agreement with varicella immunization guidelines. Prev Med 2002, 35: I 35- I 42.

II. Zimmerman RK, Bradford BJ, Janosky JE, Mieczkowski TA, DeSensi E, Grufferman S: Barriers to measles and pertussis immunization: the knowledge and attitudes of Pennsylvania primary care physicians. Am J Prev Med 1997, I3:89-97.

12. Zimmerman RK, Giebink GS, Street HB, Janosky JE: The knowledge and attitudes of Minnesota primary care physicians about barriers to measles and pertussis immunization. J Am Board Fam Pract 1995, 8:270-277.

13. Green LW, Kreuter MW: Health Promotion Planning: An Educational and Environmental Approach 2nd edition. Mountain View, CA., Mayfield; 1991.

14. AC G, EM MD: The PRECEDE-PROCEED Planning Model. In Health Behavior and Health Education: Theory, Research, and Practice Volume 17. 3rd edition. Edited by: Glanz K, FM L and BK R. San Francisco, Jossey-Bass Publishers; 1997:359-383.

15. Immunization Research Group DFMUP: Impact of 2002 Varicella Vaccine Shortage. 2005 [http://www.pitt.edu/AFShome/f/a/fami lymd/public/html/immunization/immunization-research-s.html]

16. Aday LA: Designing and conducting health surveys San Francisco, JosseyBass Inc.; 1989.

17. Zimmerman RK, Mieczkowski TA, Mainzer HM, Medsger AR, Raymund M, Ball JA, Jewell IK: Effect of the Vaccines for Children Program on physician referral of children to public vaccine clinics: A pre-post comparison. Pediatrics 200I, I 08:297-304.

18. Freed GL, Clark SJ, Pathman DE, Konrad TR, Biddle AK, Schectman RM: Impact of a new universal purchase vaccine program in North Carolina. Arch Pediatr Adolesc Med 1997, I 5 I : I I I7-I I 24.

19. Fairbrother G, Friedman S, Hanson KL, Butts GC: Effect of the vaccines for children program on inner-city neighborhood physicians. Arch Pediatr Adolesc Med 1997, I 5 I: I 229-I 235.

20. Szilagyi PG, Humiston SG, Shone LP, Barth R, Kolasa MS, Rodewald $L E$ : Impact of vaccine financing on vaccinations delivered by health department clinics. Am J Public Health 2000, 90:739-745.

21. Practices CPH: Evaluation Study of the Community Health Project: Findings and Recommendations. University of Pittsburgh Graduate School of Public Health. 2000.

22. Santoli JM, Rodewald LE, Maes EF, Battaglia MP, Coronado VG: Vaccines for Children Program, United States, 1997. Pediatrics 1999, 104:1-7. 
23. Yusuf H, Adams M, Rodewald L, Lu P, Rosenthal J, Legum SE, Santoli J: Fragmentation of immunization history among providers and parents of children in selected underserved areas. $\mathrm{Am} J$ Prev Med 2002, 23:106-II2.

24. Centers for Disease Control and Prevention: Estimated Vaccination Coverage with Individual Vaccines and Selected Vaccination Series Among Children 19-35 Months of Age by State US, National Immunization Survey, Q1/2002-Q4/2002. 2005 [http://www2a.cdc.gov/nip/coverage/nis/

nis iap.asp? $f m t=v \& r p t=t a b 3$ antigen state\&qtr $=Q 1 / 2002-Q 4 / 2002]$.

\section{Pre-publication history}

The pre-publication history for this paper can be accessed here:

http://www.biomedcentral.com/1471-2458/6/7/prepub

Publish with Biomed Central and every scientist can read your work free of charge

"BioMed Central will be the most significant development for disseminating the results of biomedical research in our lifetime. "

Sir Paul Nurse, Cancer Research UK

Your research papers will be:

- available free of charge to the entire biomedical community

- peer reviewed and published immediately upon acceptance

- cited in PubMed and archived on PubMed Central

- yours - you keep the copyright

Submit your manuscript here:

http://www.biomedcentral.com/info/publishing_adv.asp 